\title{
Editor-in-Chief (January 2014-May 2017) Farewell Report
}

I have completed my 3-year term as editor-in-chief (2014-2016), and I am pleased to hand over the task to Tiziana Catarci who took over as editor in June 2017. I feel that we have made much progress over the last 3 years, and I am proud of our accomplishments. Of course, there is much left to do to make sure that the journal increases its visibility and impact.

While "data and information quality" has been a fairly active area for almost 20 years, with many application areas and interest from practitioners, high-quality academic research on quality had a slow(er) start, compared to other topics. Quality is also a multidisciplinary area and that has both advantages and disadvantages. I had to consider all of these factors as I identified objectives for my term.

When I started my term in 2014, the journal was still experiencing some start-up challenges (from a 2009 launch). My first objective was to improve the review process, to set target deadlines, and to work closely with existing and new AEs, to provide high-quality reviews. I am pleased to report that this has been a tremendous success. We are now able to make a decision within 90 days of receiving a paper, in most cases, and in some cases, we are closer to a 60-day timeline! I will be quick to note that I could not have accomplished this without the dedicated efforts of the AEs and reviewers. In the process, we also sent out a clear message that the journal had high criteria for acceptance, and this has in turn created a virtuous cycle where the quality of submissions has increased.

My second objective was to increase the visibility of the journal and this has been done via reaching out to various mailing lists, reaching out to authors at good-quality conferences and workshops, and inviting organizers of conferences to encourage authors to submit full papers to the journal. Special issues are excellent ways to attract papers and to increase visibility. I am pleased to report that I have organized four special issues. This includes the 2015 special issue on provenance, the 2016 special issue on Web data quality, the 2017 special issue on the veracity and value of big data (ongoing), and the upcoming special issue on reproducibility in information retrieval.

When I started my term in 2014, the search committee encouraged me to reach out to multiple relevant computer science research communities, including data management and data mining. We have also experienced much growth in data science and big data, and these topics are very relevant to the journal. We recently updated the list of topics to better reflect new areas including Web and social data, sensor data, information integration, and so on.

Despite these successes, I feel that the next editor has to continue to work diligently to raise awareness, and to connect with research communities so that we have a strong steady state of submissions of research manuscripts. Ideally, we would be able to have four issues with five research manuscripts per year. Producing 20 papers as output will require about 80 to 100 papers as input, and we are making progress. On a positive note, I am confident that we can reach such a goal.

I will end this report with a note on the CHALLENGE paper initiative, a major accomplishment during my term. Senior Associate Editor Felix Naumann, who stepped down at the end of 2015, played a leadership role in this effort. Challenge papers are short two- to three-page papers that

2017 Copyright is held by the owner/author(s).

1936-1955/2017/10-ART7

https://doi.org/10.1145/3143313 
must clearly and succinctly define a challenge and then provide an outline of potential solutions. We conceived of this type of paper as a way to encourage new research and to attract new researchers to the journal. This initiative has succeeded beyond our expectations and has resulted in a deluge of submissions. That has, in turn, create a new challenge because it is sometimes difficult to identify at least two reviewers with expertise across a broad spectrum of topics. Many authors also have a difficult time writing a "good" challenge paper within this short page limit, and many papers go through two to three rounds of review. The challenge papers have played a tremendous role in raising visibility for the research area and the journal, and I encourage other ACM journals to consider introducing challenge papers. Looking forward, the incoming editor will also have to make sure that these papers result in research manuscripts, in order to make sure that we are completing the cycle of research.

I am confident that Tiziana will continue to lead the journal to greater successes. I look forward to continuing my service to the journal as an associate editor.

Louiqa Raschid

Editor-in-Chief 